\title{
AS PAISAGENS DE BERNARDO ÉLIS NA OBRA VERANICO DE JANEIRO $^{1}$
}

\author{
THE LANDSCAPES OF BERNARDO ÉLIS IN WORK VERANICO DE \\ JANEIRO
}

\section{LAS PAISAJES DE BERNARDO ÉLIS EN EL TRABAJO VERANICO DE JANEIRO}

\author{
Diogo Marçal Cirqueira \\ Doutorando em Geografia - PosGeo-UFF \\ Rua dos Inválidos, 138 bl. A ap. 304, Centro \\ Rio de Janeiro-RJ \\ 20231-046 \\ e-mail:diogogeo@hotmail.com
}

\section{Resumo}

Este artigo aborda às paisagens contidas na obra Veranico de Janeiro, de autoria de Bernardo Élis. Partimos do pressuposto que a literatura não é uma representação fiel da realidade, apesar de se referenciar nela. Por outro lado, entendemos que a literatura ou as narrativas literárias se fundamentam nas vivências, experiências e perspectivas do autor, e ele efetuando um ato artístico - não possui compromisso com a "verdade" e brinca com esta para compor o "real" e o "irreal" na obra. Assim, é necessário observar a trajetória socioespacial do literato - sua história de vida e as espacialidades que compõe simbolicamente suas vivências, afim de entendermos o processo de produção da obra e ela em si. No caso que aqui tratamos, Bernardo Élis se fundamenta em suas vivências e experiências no sertão goiano, de onde retirou referências para compor sua linguagem e representações. Isso é nítido em Veranico de Janeiro, pois, o literato não somente expressa a sociedade goiana e suas contradições marcadas no tempo-espaço, mas também a relação desta com a meio ambiente e, consequentemente, a constituição das paisagens dessa relação.

Palavras-chave: Literatura, Geografia, Paisagem, Bernardo Élis

\section{Abstract}

This article discusses about the landscapes contained in the book Veranico de Janeiro, authored by Bernard Élis. We assume that literature is not an accurate representation of reality, despite the reference of reality. Moreover, we believe that literature and literary narratives are based on the experiences, and perspectives of the author. While he is making an artistic act he does not have commitment to "truth" and plays with it in order to compose the

\footnotetext{
${ }^{1}$ Este artigo foi produzido como trabalho final da disciplina "Ambiente e apropriação do cerrado", ministrada pelo prof. Dr. Manoel Calaça no Programa de Pós-graduação em Geografia (IESA - UFG) no ano de 2007. Agradeço encarecidamente a leitura previa desse texto realizada pelos professores Dr. Alex Ratts e Dr. Eguimar Felício Chaveiro e pela professora Dra. Maria Geralda de Almeida bem como, seus enriquecedores comentários, críticas e sugestões.
} 
"real" and "unreal". So it is necessary to observe the socio-spatial trajectory of the author - his life story and spatialities which symbolically compose his experiences in order to precisely understand the production process of his work and the work for itself. In this case, Bernardo Élis composes his language and representations based on his experiences of "sertão" of Goiás. This is clear in Veranico de Janeiro, for the writer not only expresses the Goiás society and its contradictions marked in time-space, but also its relationship with the environment and, consequently, the formation of the landscape of this relationship.

Keywords: Literature, Geography, Landscape, Bernardo Élis

\section{Resumen}

Este artículo discute las paisajes contenidas en el libro "Verano de Janeiro", escrito por Bernard Élis. Suponemos que la literatura no es una representación exacta de la realidad, a pesar de la referencia en la realidad. Por otra parte, creemos que la narrativa de la literatura y la literatura se basan en las experiencias, perspectivas y experiencias del autor, y - haciendo un acto artístico - no tiene ningún compromiso con la "verdad" y juega con él "real" y él "irreales" para compor el trabajo. Por lo tanto, es necesario observar la trayectoria socioespacial del escritor - historia de su vida y espacialidades simbólicas que constituyen sus experiencias, con el fin de entender con precisión el proceso de producción y el trabajo en sí mismo. En el caso que tratamos aquí, Bernardo Élis se basa en sus experiencias en lo "sertão" de Goiás, donde retiró las referencias a componer su lenguaje y representaciones. Esto es claro en "Verano de Janeiro", porque el escritor no sólo expresa la sociedad goiana y sus contradicciones marcados en el tiempo-espacio, sino también su relación con el medio ambiente y, en consecuencia, la formación del paisaje de esta relación.

Palabras-clave: Literatura, Geografía, Paisaje, Bernardo Élis

\section{Introdução}

No presente artigo, pretendemos fazer uma abordagem da obra de Bernardo Élis Veranico de Janeiro. Um dos nossos objetivos é realizar uma análise geográfica dessa coletânea de contos ao enfocar a paisagem como elemento que fundamenta o autor, consequentemente, ambienta e coloca-se como "personagem" (LIMA, 2000) das tramas que compõe a obra.

Nesse sentido, desejamos ressaltar que as narrativas do autor fundamentam-se em vivências que o mesmo estabeleceu no antigo Estado de Goiás - que compreendia os atuais estados de Goiás e Tocantins e em territórios do bioma Cerrado. O Cerrado aqui não será entendido somente como uma fitofisionomia, mas, também, como uma vegetação que está interligada a um grupo social e, como tal, produz culturas e formas peculiares de se relacionar com o mundo, em outras palavras, conforma um "gênero de vida" (RIGONATO, 2005). Por 
conseguinte, as paisagens do Cerrado serão apreendidas nos moldes da "paisagem cultural" de Sauer (1998), isto é, como um conjunto de formas naturais e culturais associadas que interagem no decorrer do tempo e influencia indivíduos e grupos sociais. Como tal, esta paisagem é também uma produção social simbólica que vai além de uma perspectiva material e/ou imaterial e, "pode ser transmitida em forma de danças ou poemas, ou representada mediante técnicas diferentes em superfícies diferentes: pinturas na tela, texto em papel, desenhos no chão, nas rochas. Suas manifestações podem ser visíveis ou invisíveis, concretas ou imaginadas" (SEEMANN, 2007, p. 55).

A relação entre geografia e arte é um tema pouco tratado na geografia, entretanto, por conta de leituras pós-estruturalistas e pós-modernas, gera debates um tanto amplos no interior da disciplina. Algumas abordagens surgiram nos últimos anos destacando a importância da dimensão geográfica (ou melhor, do espaço) na história da arte (KAUFMANN, 2004) ou enfatizando como aspectos - metodológicos - da produção artística são importantes - ou poderiam ser - ao processo de produção do conhecimento geográfico (HISSA, 2002; HAGGETT, 1990). Estas perspectivas dão importância a feitura da arte em relação com a ciência, a sua metodologia ou a espacialidade aí contida. Aqui, seguindo um outro caminho e partindo da geografia humanística, nos centraremos no sujeito que produz a obra; suas vivências e experiências no espaço e a forma como isto é codificado em arte, ou melhor, em literatura.

Bernardo Élis, como indivíduo que teve suas vivências em territórios e paisagens de Cerrado, foi influenciado subjetiva e intelectualmente por esse ambiente. Isso fica nítido em sua obra literária, na qual, paisagens, lugares, personagens, estéticas, linguagens etc. narrados se referenciam em um modos vivendi no/do cerrado goiano (ALMEIDA, 2003).

Assim, temos em mente que para analisar uma obra devemos estar atentos ao seu conteúdo e significado, ao tempo do qual ela emerge e ao contexto espacial do qual ela surge. Tudo isso filtrado por uma "persona-lidade" e inserido em um contexto social (ALMEIDA, 2003; LIMA, 2000). Apesar disso, e tendo em vista que as obras de Bernardo Élis permitem múltiplas abordagens, daremos maior ênfase aos aspectos "ambientais" - a paisagem em especial - da obra Veranico de Janeiro.

A obra em questão é uma coletânea composta por seis contos, sendo estes: Veranico de janeiro, A enxada, Rosa, O padre e um sujeitinho metido a rabequista, Dona Sá Donana e $O$ fuxicos da fonte do Taquari. Como iremos tratar a diante, apesar de cada conto 


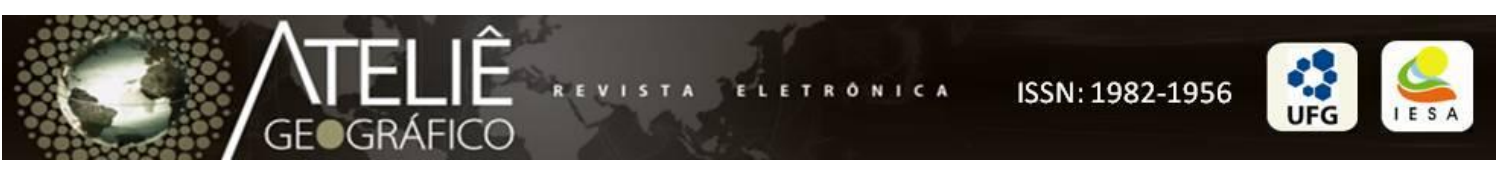

ser independente e buscar retratar questões específicas, estes constituem uma unidade na obra, pois, personagens, histórias e localidades se entremeiam e se repetem nas tramas. Isso nos dá indício de que o literato intenta compor uma localidade ambientadora para as narrativas. Além disso, o autor no título expressa também uma temporalidade, ou seja, o título que dá nome a obra, Veranico de Janeiro, denota um período do tempo climático no ano, o que, por conseguinte, carrega sentidos e significados para as pessoas que vivem no cerrado goiano. Afora isso, Bernardo Élis aventa o modo de vida dos indivíduos que vivem no "sertão goiano", e, ao tratar de aspectos culturais e da relação ser humano/natureza, expõe as contradições, conflitos, desigualdades, paradoxos e ambiguidades que aí perpassam.

$\mathrm{O}$ artigo está organizado na seguinte estrutura: primeiramente discutiremos a relação entre literatura e ciência geográfica, onde buscamos nos posicionar teoricamente; posteriormente abordamos a trajetória socioespacial de Bernardo Élis e a relacionamos com a produção de sua obra; em seguida lançamos luz sobre os aspectos geográficos da obra Veranico de Janeiro; e, por fim, analisamos as paisagens contidas na obra e tecemos as considerações finais.

\section{Literatura e ciência geográfica: entre "paralelos e paradoxos"}

Entendemos ser necessário fazer uma reflexão acerca da relação entre arte (literatura) e ciência (Geografia), tendo em vista que a literatura se encontra no campo da arte e que se configura enquanto um tema adverso ao cabedal de assuntos que a Geografia trata com maior recorrência (SEEMANN, 2007) - mesmo que se encontre presente na extensão histórica da produção geográfica (LIMA, 2000). Diante disso há a necessidade de se discutir teoricamente a relação entre esses dois campos, arte e ciência; seus paralelos e paradoxos. Obviamente, desejamos apenas nos posicionarmos; não pretendemos colocar um ponto final nessa discussão, mas, lançar luz sobre outros caminhos para se analisar o assunto.

Hissa (2002) ao discutir as "fronteiras" teóricas e epistemológicas da geografia, levanta um interessante e pertinente debate referente a relação entre ciência e arte. Segundo o mesmo, a ciência européia, constituída no bojo da perspectiva positivista, sempre buscou fugir da liberdade criativa e da subjetividade - os "erros científicos" - em detrimento de assegurar o rigor e a objetividade científica: "esse saneamento teria a finalidade de libertar o 
'homem de ciência' de sensações subjetivas, tais como o desejo, a poesia, a utopia, a necessidade de expressão artística. $\mathrm{O}$ indivíduo passaria, portanto, a 'observar cientificamente' o mundo" (HISSA, 2002, p. 58). Por outro lado, é interessante ressaltar que a produção literária segue outra direção, contudo, permanece também sobre as rédeas do positivismo. De acordo com Lejeune (in NORONHA, 2002), muitos crêem que na produção literária ao se buscar a "verdade" sai-se do campo da arte.

Mesmo que vigore esse impasse entre arte e ciência e embora um discurso pautado na contraposição entre objetividade e subjetividade seja reedificado constantemente principalmente nas discussões científicas, a "criação" na arte e na ciência não se faz sem criatividade, sem a influência da subjetividade, ou mesmo, sem um mínimo de imaginação (HISSA, 2002). Também, tanto na ciência quanto na arte - ou mesmo em um de seus ramos, como a literatura, o cientista ou o artista não podem fugir do contexto social no qual estão inseridos (GOLDMANN, 1976). Frente a isso, como bem pontua Hissa, as fronteiras entre ciência e arte são bastante tênues - ou, em alguns casos, como ele destaca, impossíveis de serem identificadas.

Apesar disso, nos fundamentando nas discussões levantadas acima, surgem alguns questionamentos: arte e ciência realmente são a mesma coisa? Os objetivos de ambas no que toca a uma leitura da realidade são os mesmos? Quais as similitudes e diferenças da ciência e da arte? São questionamentos bastante amplos e complexos, impossíveis de serem respondidos de uma forma simplista ou sem uma reflexão aprofundada. Aqui, no horizonte que nos permite um artigo, limitaremo-nos a lançar olhar junto as diferencialidades e as relações entre a literatura - entendendo esta como uma atividade artística - e a Geografia uma ciência.

Em sua flexibilidade, a literatura é uma interpretação do mundo, uma representação da realidade, que condiz a um indivíduo contido na sociedade. Estas proposições podem ser aplicadas a produção científica, no entanto, quando nos limitamos à literatura, percebemos que a relação entre indivíduo e esta permite a manipulação e a organização de palavras que produzem efeitos de sentidos que ultrapassam a pura significação do real. É justamente a amalgamação entre o real e o imaginário que transforma o desejo do autor em literatura, cujas possibilidades linguísticas e a manipulação dos níveis semântico, fonético e sintático são extrapoladas para além do formal. 
Ao falar sobre o ficcional e o real na literatura pornográfica, Moraes (2007) ressalta que, "a literatura é inorgânica. Por isso pode dizer o que quiser, pode ser irresponsável"2. Destacando a qualidade "inorgânica" a autora evoca a condição de arte e a "liberdade" de elaboração do discurso da literatura, justamente descompromissado com a realidade em si. Também, essa colocação nos faz crer que por isso a literatura se faz diferente de outras manifestações artísticas - e da própria ciência; ela utiliza-se de uma matéria prima chamada linguagem escrita, que por sua vez se configura como poética ${ }^{3}$.

No que se refere à ciência, apesar do indivíduo que a produz também estar sob influência da sociedade e buscar estabelecer uma representação da realidade, ela se diferencia da literatura no que tange a "inorganicidade" (MORAES, 2007) contida nesta. Apesar disso, não podemos perder de vista as similitudes entre ciência e literatura. Morin (2000, p. 28), por exemplo, nos fala da relação entre irresponsabilidade e produção científica: "A responsabilidade não é um conceito científico (...) Ser cientista é ser literalmente irresponsável! Isso não quer dizer que o cientista não seja responsável!”. Ou seja, o cientista deve derrubar leis, romper paradigmas, quebrar barreiras epistemológicas etc., e isso é fundamental para que o conhecimento científico caminhe. Na verdade, é justamente isso que permiti o "desenvolvimento" da ciência. No entanto, cientistas devem ser responsáveis e pensar de forma ética - e responsável - nas formas como serão realizadas e usadas sua produção científica na sociedade.

O literato, em seu ato de produção, também tem que quebrar distorcer e contorcer a linguagem e tudo que está contido nela, desde representações às concepções filosóficas. Porém, a ciência está fundada em uma perspectiva que preza por um conhecimento sistematizado e metodicamente assentado no empírico, por meio do qual busca chegar o mais próximo possível do real - isso não quer dizer que chegue. Enquanto isso, a literatura, apesar de em alguns casos almejar fazer uma leitura objetiva da realidade, devaneia na interface entre a "realidade" e o "ficcional", e isso ocorre sem nenhum compromisso com a "verdade", a não

\footnotetext{
${ }^{2}$ Programa "Café Filosófico", exibido na TV Cultura em 22/11/2007 e disponível também no sítio www.cpflcultura.com.br.

${ }^{3} \mathrm{Paz}$ (1972), ao discutir o surgimento do romance na modernidade, demonstra essa característica da literatura; ao contrário do filosofo e do historiador, o romancista não buscar ordenar idéias ou narrar fatos, mas sim "recriar a um mundo". Dentro disso, como o romance é uma produção moderna, é a antítese de si mesmo, uma vez que questiona e julga a realidade da própria realidade. Assim, como enfatiza Paz, na medida em que a prosa auto refuta-se, há o regresso da prosa ao poema; o romance deseja ser poema. É justamente por isso que a literatura é ambígua, não somente com o contexto e com quem a produz, mas também com a própria realidade.
} 


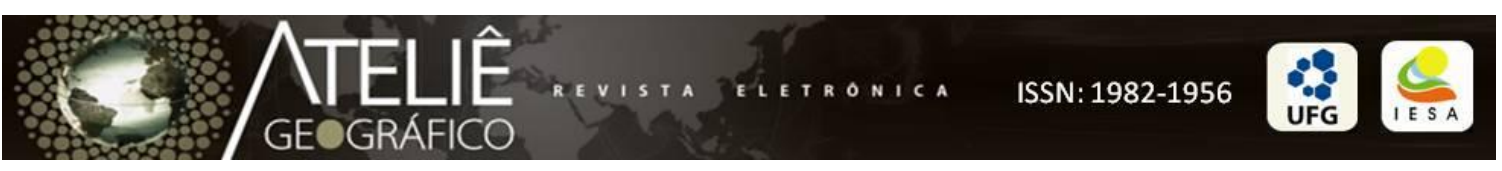

ser com a intencionalidade e objetivos do próprio autor ou autora, de forma consciente ou inconsciente.

"Uma teoria científica tem sempre a incerteza, ainda que ela possa fundar-se em dados que possam ser certos" (MORIN, 2000, p. 39). Morin, ao pontuar isto, busca ressaltar que a grande importância da epistemologia moderna consiste justamente em ter demonstrado de maneira decisiva que a teoria científica não é o reflexo do real, mas sim, uma construção do espírito que efetivamente se esforça por aplicar-se sobre o real.

Esse autor nos coloca em um embaraço: ora, não somente a ciência, mas também a literatura, são uma construção do espírito e não tocam a realidade em sua totalidade? Ambas são traduções do real numa linguagem embebida pelo olhar de um indivíduo, de uma dada cultura e situado no tempo-espaço?

Não pretendemos nos aprofundar nessas questões, no entanto, acreditamos que ciência e literatura possuem pontos em comum - dentre eles a própria mão da subjetividade influenciando na produção de ambas, mas, diferenciam-se em seus objetivos finais, ao buscarem fazer uma leitura da realidade. Como foi mencionado acima, a literatura não possui responsabilidade para com a realidade (MORAES, 2007). Já a ciência, mesmo que o cientista tenha que ser "irresponsável" ele deve ser "responsável” (MORIN, 2000), pois ela busca realizar uma leitura o mais fiel possível da realidade - e, ainda mais, pensar responsavelmente como esta leitura da realidade será utilizada para intervir na realidade.

Outro fator que diferencia arte e ciência são as formas das mesmas exporem suas metodologias de produção. Na produção científica, deve-se sempre estar explicito a metodologia adotada pelo pesquisador para se chegar a um resultado. Isso é quase que uma regra básica na produção de uma pesquisa - mesmo que em alguns casos não ocorra. Talvez este seja uma das principais características do conhecimento científico; os caminhos metodológicos percorridos devem estar expostos, e isso, exatamente, para permitir que outros cientistas o continuem. Continuar, nesse caso, significa seguir em frente, refutar e, quiçá, alterar direções ${ }^{4}$.

$\mathrm{Na}$ literatura, diferentemente, mesmo que o autor deseje expor os caminhos trilhados em sua produção literária, na maioria dos casos, isso fica oculto; é uma incógnita contida no autor e na obra. Quem sabe seja a metodologia não manifesta que proporcione a

\footnotetext{
${ }^{4}$ Ver, por exemplo, Popper (1993) e o conceito de "refutabilidade".
} 
magia da literatura e permita interpretações para além da realidade que a mesma tentou retratar.

Também gostaríamos de enfatizar que os discursos produzidos pela literatura e pela ciência - condizentes com a realidade ou não - seguem os objetivos e intencionalidades do literato e do cientista. É válido advertir que outras questões estão envolvidas nas produções literárias e científicas, como o inconsciente, a aceitação dos grupos sociais, o entendimento da linguagem pelos receptores, a influência da sociedade, a gerência das instituições etc., mas isso não retira de cena a relação autor e produção como central. A relação entre autor e obra se configura como singular, e isso une literatura e ciência.

Assim, concordamos com Said e Barenboim, quando em suas discussões sobre partitura musical, literatura e poesia observam que a produção é o "resultado de uma série de decisões tomadas pelo compositor, pelo escritor ou pelo poeta, cujo resultado é o que nós temos", e, continua os autores, "para ler o texto, é preciso tentar entender o processo pelo qual essas notas ou essas palavras se tornaram presentes no papel" (SAID e BARENBOIM, 2003, p.124).

Gostaríamos de destacar este última fragmento citado acima, pois, para se entender o texto literário, poético, musical ,e acrescentamos, o texto científico, devemos entender as condições várias que influenciaram o autor. $\mathrm{O}$ texto depois de escrito se torna um objeto independente do autor, uma vez que se cristaliza na linguagem escrita (SAID e BARENBOIM, 2003). Apesar disso, devemos ter em mente que estão contidos no texto relações sociais, temporalidades e espacialidades que influenciaram diretamente na produção efetivada pelo autor. Desse modo, para se entender melhor uma obra devemos nos atentar sobre os fatores históricos e espaciais aos quais foi concebida e acerca da própria trajetória do autor. Isso permite a compreensão do posicionamento do escritor frente a alguns fatores históricos e espaciais - tendo consciência sempre da volubilidade dessa questão.

No que se refere especificamente à literatura, Seemann (2007, p. 52) lança luz junto a essa discussão quando insere a paisagem - onde estão contidas temporalidades históricas e materialidade espacial - a ação criadora do literato, pois,

cabe dizer que a paisagem inspira o artista que, por sua vez, traduz a paisagem conforme o seu próprio olhar, sua imaginação, sua cosmologia e seus sentimentos. A poesia e a paisagem formam uma "geograficidade" (uma expressão cunhada pelo geógrafo francês Eric Dardel), que assinala a relação do homem com a Terra como "cumplicidade obrigatória" e como modo de sua existência e de seu destino. 


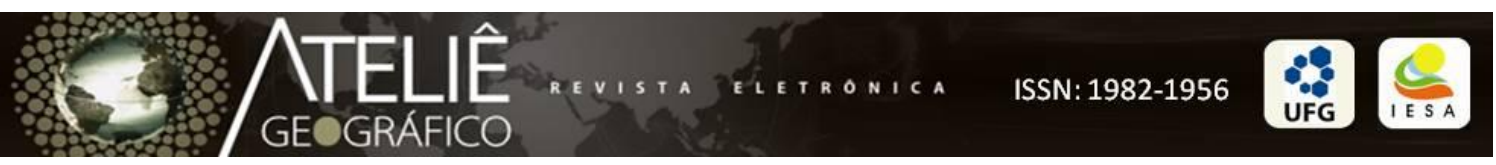

Portanto, como ponderam Said e Barenboim (2003, p. 123), "pode-se falar sobre texto e sobre estabelecer um texto", de tal modo que para fazermos a leitura geográfica da obra "Veranico de Janeiro" lançaremos um olhar, não somente junto ao texto em si, mas, também, acerca da trajetória socioespacial do autor, pois acreditamos que esta influencia nos processos criativos do mesmo. Assim como Cora Coralina para Chaveiro (2007) se relaciona com um lugar - supostamente a Cidade de Goiás - e metaforiza esse lugar, acreditamos que é no Cerrado goiano, essa espacialidade historicamente constituída, que Bernardo Élis,

se forma enquanto pessoa relacionando com a cultura que lhe apresenta os signos, os símbolos e os ritos que o transforma num agente observador ou num intérprete metafórica[o] do que lhe ocorre e do que ocorre no lugar. É do lugar que alça a sua fala, esse lugar que está na sua alma, que medeia a sua relação com o mundo, que dá sentido para a sua condição de sujeito (CHAVEIRO, 2007, p. 180).

De tal modo, a literatura é com certeza uma forma de exteriorização e representação das experiências de um indivíduo do/no espaço; um encontro entre o mundo objetivo e a subjetividade humana. "O objetivo da literatura é apresentar a experiência concreta (inclusive o tipo de experiência que temos cotidianamente) e, assim fazendo, ela nos dá uma experiência concreta...” (TUAN apud BROSSEAU, 2007, p. 30). Apesar disso, não podemos descartar a "inorganicidade" (MORAES, 2007) ou a "ambiguidade" (PAZ, 1972) da literatura, onde pode ser dito "inverdades" ou "fantasias". Como bem ressalta Brosseau (2007, p. 32-33), “muitas vezes a literatura, em seus textos, torna-se o lugar um pouco mágico ou mítico onde, em um casamento perfeito, conjugam-se os aspectos mais concretos do mundo exterior e o mundo imaginário ou subjetivo do homem".

Na Geografia vêm sendo realizados trabalhos que entendem a produção literária como um documento ou uma representação estrita da realidade (OLANDA \& OLANDA, 2009; OLANDA, 2008; VILARINHOS, 2007; BASTOS, 1998; SOUZA, 2010), o que discordamos por conta da "inorganicidade" e "ambiguidade" da literatura ${ }^{5}$. É nesse sentido

\footnotetext{
${ }^{5}$ É interessante o debate entorno do livro "O livreiro de Kabul" no que se refere ao entendimento da literatura como uma representação fiel da realidade ou representação ficcional da realidade. A autora da referido obra, Asne Seierstad, famosa por escrever histórias que retratam guerras, em que a mesma se encontra no local do conflito no momento em que este está ocorrendo, discute a produção da literatura não-ficcional sobre os conflitos ocorridos na Chechênia, Kosovo, Afeganistão e Iraque. Segundo Seierstad (2008), ela sempre fez uma relação entre literatura e a verdade, e por conta disso abandonou a academia para buscar a realidade. No entanto, apesar da mesma afirmar fazer uma leitura do real, entra em contradição ao relatar que um de seus personagens saltou para a realidade. Ou seja, "saiu do reino da literatura e entrou no mundo real, protestando contra a forma como fora apresentado: 'aquele não sou eu no livro, e não é assim que um livro sobre mim deveria ser escrito!"” (SEIERSTAD, 2008, p. 435).
} 
que desejamos aqui fugir de uma leitura estritamente realista e segura da obra de Bernardo Élis. Buscamos, por outro lado, entender a obra "Veranico de Janeiro" não como uma representação verossímil da realidade, mas, sim, como uma representação em que o literato reconstrói e questiona a própria realidade que aborda. Em fim, travamos um "diálogo" com a referida obra a partir de uma perspectiva geográfica, sem buscar expressões de verdades absolutas na mesma ${ }^{6}$.

Brosseau (2007) nos oferece aporte acerca da construção de um diálogo entre geografia e literatura. Segundo ele, geógrafos devem ter bastante cuidado ao analisar obras literárias, pois, "geografia e literatura não são vasos comunicantes" e ambas se constituem em esferas autônomas de representação, compondo duas totalidades - ou melhor, dois sujeitos, como o autor nos avisa. Deste modo, somente um método dialógico pode fazer com que se comuniquem;

\begin{abstract}
aquilo que o dialogo sugere para mim, aquilo que ele procura evitar, é a crença na capacidade da ciência de exprimir com suas palavras aquilo que o romance diz (escreve). O diálogo não é senão outro estratégia que permite que o geógrafo entre em contato com o romance, interrogando sua própria relação com a linguagem e a escritura graças a um encontro com esse outro, sem procurar assimilá-lo. Colocar o romance como sujeito, como "totalidade", não significa dizer que ele é impermeável para nós, e sim que ele tem uma maneira própria (e isso pode ser verdadeiro para cada romance particular) de produzir sentido, uma coerência de sentido que resiste aos mais sutis esforços do analista para transformá-lo em objeto. (BROSSEAU, 2007, p. 89-90)
\end{abstract}

Nesses termos, uma das questões que perpassa a análise de Veranico de Janeiro é que, talvez, ela elucide relações de um sertão goiano que tenham se perdido com o advento da atuação do meio técnico-científico e informacional e, por conseguinte, do processo de modernização do campo, que atuaram de forma fulminante no Cerrado - e em seu povo. Ao tratar do mundo rural desse sertão goiano, a obra em questão dá margem para que lancemos um olhar geográfico sobre uma temporalidade que, por mais que esteja expressa na paisagem da obra, pode ter se perdido enquanto relações junto ao espaço, uma vez que a própria sociedade que a conformou se modificou. De tal modo, cabe um questionamento para o que nos propomos: como Bernardo Élis narra e representa as paisagens desse Goiás em Veranico de Janeiro?

\footnotetext{
${ }^{6}$ Almeida (2010) enfatiza que dentre os geógrafos que trataram da literatura na Geografia encontramos duas perspectivas: alguns desses autores se preocuparam com o valor documental do texto literário para a geografia, em outras palavras, se atentaram para a representação literária da realidade geográfica; outros geógrafos focaram
} 


\section{Trajetória socioespacial de Bernardo Élis e sua produção literária}

Para se entender o posicionamento frente ao mundo por parte de um indivíduo é de fundamental importância que lancemos luz sobre sua trajetória. Nesse caso, em que pretendemos enfatizar as paisagens na obra literária de Bernardo Élis, é mais importante ainda analisar a trajetória socioespacial desse literato, visto que, como avisa Lima (2000), a literatura é a expressão das experiências do autor com o meio, em outras palavras, a literatura é fruto das experiências do autor no espaço e, ao mesmo tempo, é seu olhar sobre os lugares e paisagens.

Entendemos, dessa forma, que as trajetórias possuem uma dimensão espaçotemporal, pois, pressupõem que os indivíduos perpassam por um repertório de lugares no decorrer de suas vidas, os quais são experienciados, significados e interpretados. Esses lugares, além de influenciar os indivíduos, firmam-se como marcos simbólicos destes e configuram-se como referências nas "passagens" de suas vidas (CIRQUEIRA, 2010).

Dando aporte a essa assertiva, De Certeau (1984), ressalta que as trajetórias evocam um movimento temporal no espaço e a unidade de sucessivos "pontos" percorridos; a trajetória ao ser desenhada por seus agentes sociais permite a formulação de suas perspectivas, visões de mundo, esperanças e desesperanças. Isso nos permite afirmar que os lugares (TUAN, 1983), como os "pontos" mencionados pelo autor, são os nós das trajetórias dos indivíduos, pois, estes significados permitem a demarcação das experiências no espaço ${ }^{7}$.

Em linhas gerais, trajetória socioespacial envolve a história de vida dos indivíduos; suas experiências dentro de uma temporalidade e uma espacialidade que não possui uma constituição linear ou contínua (BOURDIEU, 1996). A importância da espacialidade se faz na medida em que as experiências não se dão no nada, e muitas vezes, os lugares - como os "pontos" mencionados acima, demarcam momentos e limites dessas trajetórias, firmando-se como referências simbólicas e experienciais para o indivíduo. Como bem denota Tuan (1983, p.94), "sagrado e enraizado, o lugar permanece no íntimo das pessoas ainda que metamorfoseado ou devastado [em sua materialidade]".

geograficamente o valor do reflexo das condições materiais de produção literária. De alguma forma buscamos conjugar ambas as perspectivas, mesmo nos abstendo de fazer uma leitura realista da obra literária.

${ }^{7}$ A qualidade e a intensidade das vivências do indivíduo no espaço são colocadas por Tuan (1983) como fatores de extrema importância para a constituição dos lugares. 
É na conformação desses lugares por Bernardo Élis - em uma cidade interiorana influenciada marcadamente pelo mundo rural, que ele pôde estabelecer uma representação da sociedade e das paisagens do Cerrado em sua obra. Nascido na Cidade de Corumbá de Goiás em 1915, o autor obteve contato com uma realidade histórica e espacial que deram o tom das temáticas de seus livros. Além disso, deve ser enfatizado que, provindo de uma família de comerciantes e funcionários públicos com um relativo status social, Bernardo Élis muito cedo teve acesso ao ensino formal - o que era uma raridade naquela época -, o que, de certa forma, o facilitou em sua carreira de literato.

Também, em casa, Bernardo Élis teve sua principal influência; seu pai, Erico Curado, que, além de exercer a profissão de comerciante, era poeta e escritor. Erico Curado, muito atento a produção literária que vinha sendo realizada no início do século XX no "litoral" do país, escrevia vários poemas, dos quais muitos eram editados em jornais de Corumbá. Ele inclusive chegou a publicar dois livros de poemas. Nas palavras de Bernardo Élis:

poeta e homem possuidor de boa cultura, sem embargo de seu autodidatismo, e de seu contato com o Rio de Janeiro, São Paulo e o litoral, meu pai era admirador incondicional dos artistas. Para ele, um poeta, um romancista, um contista, um ensaísta estava acima de qualquer Napoleão, de qualquer Henry Ford. Morando nos cafundós de Corumbá, assinava jornais, revistas literárias e se mantinha em dia com a literatura. (ÉLIS, 1979, p. xiii-xiv)

Assim, o pai, afeita às artes literárias, incentivou Bernardo Élis ainda criança a realizar leituras das ditas "grandes obras da literatura", e como o mesmo coloca, "muito cedo, meteu-me nas mãos Os Lusíadas, Memórias Póstumas de Brás Cubas, A Cidade e as Serras, Iracema, o Guarani, Inocência, Os Mártires do Cristianismo, Nova Floresta de Manuel Bernardes e outras desgraças semelhantes" (ÉLIS, 1979, p. xiv).

No entanto, como expresso na citação, Bernardo Élis se mostrou avesso ao que lhe chegava como "boa literatura", uma vez que esta era completamente adversa a sua realidade e vivências no interior de Goiás. Ele ressalta acerca disso que,

a partir de 1930 comecei a ler suplementos literários, onde modernistas de então escreviam coisas. E suas coisas eram aquelas coisas que eu via diariamente e com as quais me encantava. Comecei a perceber que havia uma ligação entre literatura e vida cotidiana, coisas que não percebia em os Lusíadas ou em Eça de Queirós (...) Em 1935, caiu-me nas mãos a bagaceira, depois li Zé Lins do Rego: aí senti 
necessidade de contar coisas como esses contavam e percebi que muito havia que contar (ÉLIS, 1979, p. xiv).

O modernismo brasileiro e sua concepção "libertária" da criação artística, juntamente com os literatos, contistas e poetas que seguiam esse corrente, influenciaram profundamente Bernardo Élis; "tais autores me mostraram que os grandes autores não eram senão pessoas como nós mesmos e isso foi para mim muito importante" (ÉLIS, 1979, p. xvi).

Bernardo Élis, se referenciando nessa perspectiva e com a prerrogativa de que "não precisaria se guiar por outras leis que não as de sua própria interioridade e de seu próprio arbítrio" - como postulava o movimento modernista da época, pode fazer uma literatura espelhada em suas vivências e experiências. Os "banhos de corgo", a participação nas festas do catolicismo popular, a relação com a "roceirama", as estórias de assombração, o trato com as cabras, o gado, as chuvas etc. deram o tom das obras bernardianas (ÉLIS, 1979).

Bernardo Élis não somente tratou e retratou o modo de vida rural do interior goiano em suas obras. Uma das questões também evidenciadas, dentro dos vários assuntos abordados, foi à relação íntima entre sociedade e natureza, e suas reverberações mútuas. Essa perspectiva do literato entra em consonância com algumas idéias acerca da paisagem na Geografia. Berque (1999, p. 84), por exemplo, demonstra isso quando afirma que, "a paisagem é uma marca, pois expressa uma civilização, mas é também uma matriz porque participa dos esquemas de percepção, de concepção e de ação - ou seja, da cultura - que canaliza em um certo sentido, a relação de uma sociedade com o espaço e com a natureza ,e portanto, a paisagem do seu ecúmeno”.

Bernardo Élis aponta essa relação íntima entre paisagem e sociedade em suas obras - em especial em Veranico de Janeiro. E, além disso, como fica marcantemente expresso em Notas Autobiográficas ${ }^{8}$ na introdução da obra mencionada, ele próprio é um reflexo dessa relação dialética. De forma que,

por um lado ela[a paisagem] é vista por um olhar, apreendida por uma consciência, valorizada por uma experiência, julgada (e eventualmente reproduzida) por uma

\footnotetext{
${ }^{8}$ Em nosso entendimento a Nota Biográfica escrita por Bernardo Élis e alocada na introdução de Veranico de Janeiro possui um papel fundamental para o entendimento da obra como um todo. Acreditamos que o literato, intencionalmente, enfatiza aspectos de sua vida nesta Nota que possuem relação com as construções narrativas presentes nos contos; implicitamente o autor nos apresenta, a partir de sua vida, referências para o que vai ser lido. Muitas dessas referências possuem conexão com suas vivências e experiências no interior de Goiás, principalmente de sua infância em Corumbá e na Cidade de Goiás, como pode ser visto.
} 
estética e uma moral, gerada por uma política, etc. e, por outro lado, ela é matriz, ou seja, determina em contrapartida, esse olhar, essa consciência, essa experiência, essa estética e essa moral, essa política etc. (BERQUE, 1999, p. 86).

As obras bernardianas refletem essa relação, pois, o autor a partir de seu "espaço existencial" no Cerrado e em um contexto cultural específico pôde elaborar uma representação dessas paisagens na literatura.

Concordamos aqui com Lévy (apud BROSSEAU, 2007), quando esse afirma que há uma relação entre o conteúdo da obra e a existência do autor, apesar de, como o mesmo autor nos lembra, não há um determinismo mecânico entre "psicogeografia e autor".

Isso é evidente em Veranico de Janeiro, já que, provavelmente os enredos que são narrados nos contos ocorrem em Corumbá de Goiás, cidade onde nasceu Bernardo Élis. Mesmo que não seja explicitado, isso pode ser observado a partir dos marcos espaciais narrados pelo autor nas paisagens dos contos. Por exemplo: o "Rio Corumbá", a "fonte do Taquari", o "morro dos Pirineus" etc., lugares onde o próprio Bernardo Élis passou sua infância:

de tudo, porém, o que melhor havia em Corumbá era o rio, Rio Corumbá chamado, amigo e generoso, correndo sobre lajedos e brancas areias, despencando das fraldas dos Pirineus as águas frias e muito limpas (...) à sua margem ensolarada estávamos nós desde a manhã até a tardinha. Eram os banhos, os longos banhos: nosso esporte, nossa higiene, nossa escola para os segredos do sexo e da alma (ÉLIS, 1979, p. ix).

Como podemos observar Bernardo Élis se fundamentou em seu "espaço existencial" para fazer sua literatura. Apesar disso, mais uma vez ressaltamos, não podemos perder de vista que uma obra literária está a mercê da liberdade criativa do autor. Um bom exemplo disso está presente na narrativa de Bernardo Élis (apud ALMEIDA, 2003, p. 53) sobre seu processo de criação:

Grande parte de minha literatura é a descrição, a meu jeito, de paisagens e coisas de Goiás e do Brasil. Vou tentar encarrear alguns exemplos. Na elaboração de $\mathrm{O}$ tronco, como eu não conhecia a região e a cidade de São José do Duro, verdadeiro local dos acontecimentos, recriei mais ou menos a minha cidade natal - Corumbá cujos habitantes eram parecidos, mesmo porque era numerosa a população baiana naquele município.

Ou seja, apesar de trabalhar com descrições e partir de um fato verídico, o autor, por não conhecer de perto tal fato ocorrido em uma localidade, busca outros artifícios para 
representá-la na obra literária; tenta recompô-la justamente a partir de uma realidade semelhante.

Veranico de Janeiro é conformado justamente por isso, as vivências, experiências e impressões reais de Bernardo Élis sobre algumas lugares de Goiás e suas genialidade criativa que, referente a alguns componentes espaciais de sua obra, desloca, imbrica, cria e recria paisagem no tempo-espaço.

\section{VERANICO DE JANEIRO: estiagem de verão, estiagem da vida}

Quando nos propomos a discutir a obra Veranico de Janeiro e suas paisagens uma das questões que nos chamou atenção foi seu próprio título, pois o seu significado está ligado estritamente a uma manifestação metereológica e encontra representações tanto no meio científico quanto no linguajar popular. Resumindo a perspectiva científica, a enciclopédia virtual Winkpédia (2008) nos proporciona uma definição geral do fenômeno; segundo ela, o veranico é comum nas regiões meridionais do Brasil, onde é marcado por um período de estiagem com calor intenso $\left(25^{\circ}-35^{\circ} \mathrm{C}\right)$, forte insolação, e baixa umidade relativa em plena estação fria, com uma duração mínima de quatro dias, as vezes se prolongando por várias semanas.

Apesar da enciclopédia se remeter ao veranico como uma manifestação que ocorre nas regiões ao sul do Brasil no período de inverno, esse termo possui especificidades regionais no que se refere ao período de sua ocorrência. Por exemplo, enquanto no Sul o veranico ocorre no inverno - geralmente em abril, no Nordeste e Centro-Oeste ele incide em outro período do ano, especificamente no verão ${ }^{9}$, entre os meses de Novembro e Fevereiro, quando as chuvas são mais recorrentes nessas localidades. Como nos adverte o pequeno agricultor Antônio Marçal da Silva ${ }^{10}$, o veranico ocorre no estado de Goiás no mês de janeiro. Inclusive, segundo ele, é nesse mês que os agricultores aproveitam o momento de estiagem -

\footnotetext{
${ }^{9}$ Ressaltamos que no dito popular, nas Regiões Centro-oeste e Nordeste especificamente, há uma inversão no que se refere ao verão e inverno "científico". Em regiões de Cerrado, por exemplo, inverno é um período chuvoso (o verão "científico"), enquanto o verão é considerado um período de estiagem em que as chuvas são escassas (o inverno "científico").

${ }^{10}$ Entrevistado em 25/08/2008
} 
o que facilita o manuseio da terra - para cultivar o feijão ${ }^{11}$. Essa colocação encontra par numa passagem do conto Veranico de Janeiro, quando o carreiro ${ }^{12}$ e seu carro-de-boi ${ }^{13}$ ao deixarem um doente aos cuidados de Dona Chiquinha, "de para manhã voltaram para a roça aproveitando o resto do veranico, que a lua nova principiava e as chuvas iam pegar de novo" (ÉLIS, 1979, p. 19).

Assim, mesmo que existam períodos meteorológicos específicos em que ocorra o veranico em cada região, há em comum, no que se refere à concepção desse termo, o fato do mesmo caracterizar um período de estiagem num momento que a chuva é ou deveria ser recorrente. Isso, tanto para uma posição científica, quanto para uma perspectiva popular.

Como foi colocado acima, esse é um fenômeno que ocorre em Goiás geralmente em janeiro, desta forma, o título da obra em questão - Veranico de Janeiro - está estritamente ligado a um fenômeno meteorológico recorrente em áreas de Cerrado goiano. Apesar disso, por que Bernado Élis batizou sua obra com o nome desse fenômeno meteorológico? Qual a relação do título Veranico de Janeiro com a narrativa dos contos?

Ainda que a obra se configure em uma coletânea de contos, cada qual não existe por si só. Os contos não só possuem uma correlação - o que dá sentido a obra como um todo, como também há uma conexão entre estes no que se refere à narrativa. Isso pode ser observado a partir da atuação de mesmos/as personagens em contos diferentes, ora como personagens principais, ora como personagens coadjuvantes. Temos como exemplo os/as personagens: "Capitão Benditão", "Desidéria", "Elpídio", "Chiquinha do Amaro", "Dona Sá Donana”, "Evangelista”, “Dondom”, “'Otomove', o bobo que carregava a mãe nas costas” etc. Isso, inclusive, reforça a ideia de que há também uma conexão espacial na narrativa, ou seja, as tramas ocorrem em uma mesma "espacialidade ambientadora".

De tal modo, acreditamos que o título Veranico de Janeiro é utilizado pelo autor como metáfora estruturante da obra para se remeter à vida cotidiana de uma comunidade. $\mathrm{O}$ termo veranico é utilizado em sua variável regional, e ele não é usado ao acaso, visto que a sua manifestação enquanto fenômeno da natureza define uma localização - alguma região do estado de Goiás - e uma temporalidade - o mês de janeiro. Isso também é evocado para

\footnotetext{
${ }^{11}$ As afirmações do pequeno agricultor se confirmam também no Dicionário do Brasil Central, no qual veranico de janeiro é "o período de estiagem de cerca de 20 dias, entre as chuvas de dezembro e de fevereiro em Goiás" (ORTENCIO, 2009, p. 771).

${ }^{12}$ Condutor de carro-de-bois, ver Ortencio (2009).

${ }^{13}$ Transporte conduzido por bois típico nos sertões brasileiros.
} 
ressaltar as contradições existentes nessa comunidade, pois os temas presentes na obra, como a morte, a subjugação, a exploração, a violência (física e psicológica), o sexismo, o coronelismo, o racismo etc. são sinônimos de uma "estiagem durante a estação chuvosa, com dias de calor intenso e insolação" (AGRITEMPO, 2008). Essa estiagem, essa seca em período de chuva, metaforiza os problemas sociais e individuais existentes no sertão goiano. $\mathrm{O}$ veranico é a estiagem que atua na vida das pessoas, contudo, num período que deveria estar chovendo, que deveria estar radiante de vida; em outras palavras, as pessoas vivem em seca em um local onde seria possível uma existência plena, sem problemas sociais ou pessoais.

Não poderíamos deixar de fazer aqui uma analogia com o romance "Vidas Secas" de Graciliano Ramos, pois enquanto nessa obra os personagens "Fabiano", "Sinha Vitória", o "menino mais velho", o "menino mais novo" e a cachorra "Baleia" no semi-árido nordestino seco vivenciam agruras devido a falta de chuva - ou seja, "vidas secas", em Veranico de Janeiro, que representa em suas narrativas um local onde a chuva é abundante; "onde tudo que se planta dá", a problemática social, eivada pela exploração e violência, definem as "secas em vida" dos personagens.

Bernardo Élis, na supracitada obra, trata do modo de vida das pessoas do sertão goiano e suas contradições. No entanto, como já dito, o mesmo não se restringe as relações sociais, mas, também, as próprias reverberações da natureza junto aos indivíduos e na própria comunidade. De certa forma os aspectos naturais também se tornam personagens em Veranico de Janeiro, já que os mesmos compõem os enredos e influenciam consideravelmente nas tramas.

A terminologia Veranico de Janeiro utilizada pelo autor também está diretamente atrelada a manifestação natural chuva. Assim, influenciando também nos enredos, a chuva ocorre em todos os contos, seja no estado de precipitação - "aí, disparava a chover, poder d'água, com o capim crescendo, com os muros caindo, com os rios enchendo e levando os pontilhões, derrubando ranchos, carregando vacas, porcos e bezerros" (ÉLIS, 1979, p. 128) - ou em sua ausência - "Chuva não tardaria. Urro de jumentos, rascar impertinente de "rapa-cuias", gritos estrídulos dos pica-paus cutucando a guariroba, a ronda do gado pelos currais, berrando, berrando - tudo indicava as águas do iniludível" (ÉLIS, 1979, p. 65).

Cremos que Bernardo Élis realiza isso, não somente para dar relevo as contradições citadas acima, mas a fim também de destacar a chuva como marcadora do tempo 
do modo de vida rural e realçar a dimensão simbólica dessa ação física-meteorológica junto aos indivíduos, o que em determinados momentos não deixa de ser contraditório, como podemos notar no trecho seguinte:

- Chuva não deve de tardar - comentava o capitão, espreitando o céu encardido. - A chuva... - Neca repetia a palavra num eco, a boca seca, dente no dente. Não tinha terras para lavrar, nem gado para tratar, nem dinheiro para comprar mantimento quando viessem as colheitas. Por tanto, tanto fazia chover como não.

Quem se entusiasmava era o Maneta. Desentocando-se da Rua da Palha e vinha trocar idéias:

- Eh, capitão, escuitou esta noite os guaribas? Choraram bonito pras bandas do Engenho, chamando chuva. (ÉLIS, 1979, p. 69)

O conto Rosa é o que melhor representa essa relação entre indivíduo e natureza, ou melhor, entre indivíduo e chuva. Rosa, a personagem do conto, uma jovem mulher saída da zona rural para a uma pequena cidade, cujo "o pai morrera, ficando sozinha nesse mundão de meu Deus. Que morava longe toda a vida, num lugar que tinha serras altas luminosas, com um rio escuro e gemedor" (ÉLIS, 1979, p. 62), surgiu de repente na casa do Capitão Benedito e Dona Rita:

Uma mulher lá surgiu, pedindo louvado:

- Sus Cristo, patrão!

Dona Rita se levantou, o fôlego parado, emocionada, e foi atender:

- Bom dia, você...

- É. Num vê que a gente...

Sim. Era Rosa. Queria morar ali, poderia cozinhar, lavar roupa.

Como sugere Loures (2010), o motivo dessa chegada repentina de Rosa, além da morte de seu, é a seca no cerrado goiano que a atingiu. Isso se justifica, segundo a autora, pelo comportamento da personagem frente a um "pau seco" e o fato dela deixar para trás uma "serra que brilha", o que evidencia a presença de folhagem seca e de afloramentos de roças expostas. Além disso, cremos que Bernardo Élis busca também conformar um efeito de transmutação entre Rosa e a chuva na narrativa no que concerne as suas manifestações e temporalidades; pois Rosa é a chuva e chega em um período temporal de seca; surgi como a chuva no Cerrado, de repente e para ficar - ao menos por um período. 
No decorrer do enredo Rosa se coloca calada, avessa a "prosas" com estranhos e introspectiva enquanto trabalha:

calma, sempre séria, nunca loquaz, ela ficava um tempão danado quieto na cozinha, numa quieteza tão humilde e vegetal que a gente tinha a impressão de que ela se dissolvia no ambiente. (...) Sá Rita tinha que deixar de lado a costura e vir acordar Rosa de seu estupor. Nesses momentos, os olhos dela tinham um palor vítreo e manso, estampando paisagem de céu fumacento, imensas pradarias amarelentas pela seca (ÉLIS, 1979, p. 63).

No entanto, quando "vesprando chover" ela se modifica:

Fins de julho, sem mais nem menos. Rosa pegava a olvidar as coisas e recolher-se nos seus mutimos rodeados de aves.

Outras vezes era ali mesmo na varanda, no cabo do ferro de engomar, os olhos entrevados num rumo qualquer e uma ânsia tenebrosa no focinho e nos membros. Era ver um tronco seco de pau. Mas nunca sossego físico poderia dar idéia de tanta força, de tanto movimento: seres suarentos, enovelados em músculos, derrubavam campos e matas; lutas, queixumes margos de morte, de transes dolorosos de ingratidão e sofrimentos ignorados; vozes falando linguagem pesada de feitiços e superstições; muitas murmurações povoavam o silêncio da mulher.

Eram as chuvas. As águas que se aproximavam. (ÉLIS, 1979, p. 63)

Bernardo Élis, como podemos notar, expressa a influência da chuva na subjetividade e comportamento dessa personagem:

Rosa então não tinha parada. Só, cantava num tom gutural canções de uma simpleza desconcertante, com longas vogais se repetindo nessa monotonia de resmungo, de gungunado de prece, soluço de negro remando em rio, gemido de gente cavando fundo.

Oiê tire lãs-ca...

Coquê-ro

de cinco fruquia

é de ma-mauê (ÉLIS, 1979, p. 63).

Dessa forma, em um lugar diferente de onde morava; frete a uma situação que lhe causava confusões e dúvidas, Rosa sofre modificações em seu ser com a ocorrência da chuva. Assim como esse fenômeno meteorológico transforma e renova a vida no Cerrado, também influencia a personagem em sua forma de se posicionar frente as questões do mundo. Rosa vai embora. Entretanto, fica a dúvida: vai procurar uma nova vida? Vai voltar a velha vida? Isso não nos é explicitado por Bernardo Élis, mas ela vai embora, em busca de algo, 
alguma coisa que lhe de sentido. Vai-se como chegou, de repente, assim como as chuvas de veranico no Cerrado.

(...) Sol brilhando nas gotas d'água suspensas das folhas, dos galhos, dos ramos, dos brotos de capim; sol se refletindo nas poças d'água no chão, onde a enxurrada cavara profundas grupiaras. A gente via parece que uma flor, que ia pegar, sía avoando: era um besourinho.

Para o sul, nuvens brancas viajando. Na encosta fronteira, uns frangalhos de névoa diluindo-se ao sol.

Quem fazia o café era dono Rita. Rosa não estava em casa: “já estou cansada de procurar essa maluca. Será que fugiu, meu Deus do céu?".

Como Rosa fazia anualmente após a primeira chuva, rosa pela madrugada havia plantado todo o quintal, como se fosse uma roça do sertão. Perto do canto do muro estava encostada a enxada, pesada de barro fresco, o cabo também enlameado, dando a impressão de que rosa andara revolvendo a terra com as mãos.

Em cada cova viam-se nitidamente os sinais dos pés de rosa (...) Ela havia pisoteado as covas depois de plantadas. As chancas estavam claras no barro mole e peganheto de humo. As pegadas eram visíveis também nas lajes da escada que dava do quintal para a cozinha, onde ficara a marca do dedão esparramado, sujo de lama; prosseguiam como que latejantes pelo chão batido da cozinha, atravessavam a varanda que era de tábuas, ganhavam o corredor que era também de lajes, e daí pegavam a calçada da frente da casa, quase apagadas já, aprofundando-se a seguir sobre os tenros e quase transparentes brotinhos de capim que recobriam o largo como uma casimira das boas, para enfim se perderem na imensidão do largo rebrotado e se reverdecendo (ÉLIS, 1979, p. 71-72).

Bernardo Élis, em suas próprias Notas Autobiográficas, ao relatar suas vivencias

de infância na casa de seus avós, destaca as transformações que as chuvas ocasionam no Cerrado goiano. Segundo ele,

dada a formação geológica pedregosa de Goiás, a seca esturricava tudo, as águas secavam, não se viam senão uns poucos ramos verdes, o calor era insuportável: tudo e todos, em fins de setembro, clamavam por chuvas, as quais tardavam a vir. Quando vinham, uma transformação maravilhosa se dava na natureza: tudo rebrotava, de todo ponto corria água, de toda loca pulava um sapinho, de cada folha voava um pássaro, um besouro, um grilo, um inseto dourado feito uma jóia. Com os primeiros chuviscos, o quintal se cobria de um veludo de capinzinho nascendo. Meu avô ia para o quintal e fazia casas de fazenda, com currais, porteiras, moirões para custeio de gado, uma perfeição. Mais perto da casa, ele puxava um reguinho de enxurrada, confeccionava um monjolinho e assentava a máquina. A chuva batia e ele já estava deliciando-se com a socação do monjolo. (ÉLIS, 1979, p. xii-xiii).

Como podemos notar o literato não ressalta somente as mudanças que as chuvas proporcionam no meio natural, mas, também, no espírito das pessoas que vivem nesse ambiente, como está expresso em seu avô. Talvez fosse essa a intenção de Bernardo Élis no 
conto Rosa - quiçá, na totalidade da obra Veranico de Janeiro; indo além das transformações ocasionadas pela chuva no meio físico, evidenciar esta influencia na subjetividade das pessoas do sertão goiano.

Apesar disso, devemos ressaltar que a chuva não é o único aspecto natural tratado pelo literato em Veranico de Janeiro. Como já mencionado, ele realiza uma profunda abordagem das paisagens em suas obras, sobretudo em Veranico de Janeiro, e ao narrar e descrever paisagens, ele trata de outras feições da natureza e da "natureza morta" (VIEIRA, 2000), como veremos no tópico seguinte.

\section{AS PAISAGENS EM VERANICO DE JANEIRO}

Um dos aspectos interessantes da obra de Bernardo Élis, além de sua estrutura narrativa, reside na utilização do recurso das descrições. $\mathrm{O}$ autor em sua escrita estabelece uma descrição aguçada das figuras dramáticas e das paisagens que ambientam os enredos. Isso leva a uma visualização acentuada, mesmo que imagética, por parte do leitor das paisagens e contextos em que se inserem os personagens.

Ressaltando esse aspecto na obra de Bernardo Élis, Vieira (2000), ao discutir a "visualidade da linguagem descritivo-narrativa", denota a analogia da estrutura narrativa do autor com a do cinema:

a estrutura narrativa de Bernardo Élis se equipara à do cinema não só no uso da técnica da alternância ou superposição dos planos, real e irreal, como também no uso de close-up expressivos (...) A composição deste [o conto "Uma certa porta], e de outros contos de Bernardo Élis, resulta de uma síntese de planos opostos - do real e do imaginário - em que o autor joga com os recursos da sintaxe cinematográfica, usando o close-up, o flash back, a fusão de imagens, a dissolvência e a superposição de tomadas diferentes (idem, p. 22) .

Já Brandão enfatiza a relação da narrativa de Bernardo Élis com a pintura. Segundo o mesmo, "vemos o homem e a natureza retratados com pinceladas geniais, com as tintas berrantes e alucinantes de um Van Gogh" (BRANDÃO apud VIEIRA, 2000, p.22), e, na exposição de Vieira (2000, p.45), "é através de uma linguagem plástica e da configuração visual dos personagens, num verdadeiro trabalho de pintor, que Bernardo Élis induz o leitor a ver nas criaturas seu lado invisível e essencial". Inclusive, são as descrições de "cenas" 
presentes nas obras bernardianas que levam Vieira (2000, p. 23) a identificar nestas a manifestação de uma estética expressionista e impressionista:

Na obra de Bernardo, convivem duas tendências estéticas opostas, mas não contraditórias: uma impressionista, quando o autor se ocupa da descrição da natureza, outra expressionista, quando o autor volta-se para a caracterização dos personagens.

A discussão realizada pelos autores acima dão relevo as descrições realizadas por Bernardo Élis em suas obras, e, apesar destes enfatizarem as características expressionistas, ou seja, a caracterização dos personagens humanos, há uma abordagem profunda da "natureza morta" e dos aspectos naturais - designadamente do bioma Cerrado - compondo as narrativas do literato.

A descrição das paisagens é um artifício utilizado constantemente por Bernardo Élis em Veranico de Janeiro, de forma a estas se estabelecerem como um dos condutores dos enredos. Acreditamos que em alguns momentos as paisagens narradas por Bernardo Élis ultrapassam a posição ambientadora, estas se imbricam na trama da narrativa, na subjetividade e vida dos personagens; os aspectos naturais ou a "natureza morta" são caracterizadores da narrativa. Arriscaríamos dizer aqui que as paisagens são personagens em Veranico de Janeiro.

Podemos observar isto no trecho abaixo retirado do conto Dona Sá Donana, no qual ele expressa uma fineza ao narrar aguçadamente as paisagens:

A casa era um casarão acaçapado, chato, de beiral enorme, daqueles de caixão, pintado de um azul que hoje não se usa mais; as janelas e portas eram em arco, de vinhático ou pau-d'arco, muito grossas, envidraçadas de vidros brancos e azuis. A caçada também era muito larga, de laje de quartzito. (...) repartindo-a em dois corpos, havia um largo corredor úmido, de laje, que saía na varanda, como chamavam a sala de jantar. A varanda era assoalhada com largas tábuas ringideiras, de teto baixote telha-vã, com largas janelas dando para um pátio interior igualmente calçado de laje, em cujos canteiros cresciam rosas bandalhas, amarelas, brincos-deprincesa, gerânios, jasmins-do-cabo, guerra-de-amor e dálias. A varanda e a cozinha tinham um porão, pois sendo inclinado o terreno, enquanto a entrada da casa estava no rés-do-chão, as partes do fundo estavam a uma altura de dois metros. Abaixo desse pátio vinha o quintal com as fruteiras e depois o curral que dava para o rio e daí para o campo aberto, para os pastos. (ÉLIS, 1979, p. 77).

Cosgrove (1998), fundamentado no pressuposto de que toda paisagem é simbólica, pontua que a paisagem é um "texto cultural". O autor ressalta isso para alertar os 
pesquisadores geógrafos que a paisagem oferece uma gama de dimensões e possibilidades de leituras e estes devem ficar alerta para que não sobreponham seu "olhar" ao verdadeiro sentido da paisagem analisada. $\mathrm{O}$ autor, assim, demonstra que, na maioria dos casos, para se analisar e entender uma paisagem específica deve-se compreender os códigos e significantes culturais que a atravessam. Caso isso não ocorra, há o risco de se realizar uma abordagem distorcida da realidade.

Em Veranico de Janeiro Bernardo Élis demonstra um profundo conhecimento dos códigos simbólicos das paisagens que descreve e narra. Possivelmente, isto é reverberação de suas vivências e estudos no/sobre o Cerrado e o sertão de Goiás ${ }^{14}$. Na citação que se segue, o literato, por exemplo, demonstra um profundo conhecimento físicomorfológico das paisagens que narra, o que ele relaciona com a apresentação precisa de localização do estado e uma nomenclatura toponímica especifica da região:

Pela sua frente, estendia-se aquela largueza sem fim que são os horizontes amplos do Planauto Central, eito de chão que pega da base dos Pireneus até os confins da Bahia, abrangendo as águas vertentes do Tocantins para cá, do São Francisco para acolá e do Paranã mais assim pressa bandinha de lá. No caixa-prego, contornos acinzentados de serras, as chapadas se sucedendo em planos e planos. Até a serra dos Veadeiros, naquele nunca-se-acabar e horizonte, era uma pincelada azul-cinza, apaga-não-apaga e tão recuada.

Por perto, as curvas femininas dos morrotes, a delicadeza de pintura dos capões indicadores das manchas de terras férteis naquele oceano de campina verde. (ÉLIS, 1979, p. 87)

De acordo com Santos (1997, p. 61-62), as paisagens estão ligadas a dimensão da percepção, do que chega aos sentidos, e "esta pode ser definida como o domínio do visível, aquilo que a vista abarca. Não é formada apenas de volumes, mas também de cores, movimentos, odores, sons etc.”. Nesse sentido, uma vez que a paisagem está ligada ao sensorial, ela é dinâmica e se diferencia de acordo com os indivíduos e grupos que a percebem.

Dando sentido a concepção de Santos e contrariando a ideia de paisagem como algo estática, Bernardo Élis nos narra uma paisagem viva e em transformação constante ao evidenciar uma profusão de nuances de cores, de cheiros, de gostos, de sons, enfim, uma 
materialidade geradora de impressões diversas no indivíduo - e mais do que nunca, no imaginário de quem o lê:

Na rua paradíssima, o capim secava com a seca. Um ou outro boi cambaleante de magro vinha roer a grama meia verde dos lugares úmidos, como ali perto da bica e ao longo do rego que levava as águas servidas da casa do Capitão Benedito para a grota. Papa capins e passo-preto desciam em nuvens sobre o chão, cantando aqui e acolá as restantes sementinhas de capim numa camaradagem íntima com o boi magrelo e tristonho (ÉLIS, 1979, p. 64).

Aglomerado na frente da igreja, o pessoal da cidade olhava para a encosta fronteiriça, doutra banda do rio, por onde torcicolava a estrada que levava para a Prata. A encosta era alta, cheia de tufos verdes de marmelada-de-cachorro, lobeiras, pindaíbas e paus-terras. Nesse tapete verdolengo, a estrada era um traço rubro, ora brancacento. O dia, era um encanto de dia. Muito sol, a orvalhada rebrilhando como se fosse brilhante, restos de névoa navegando ao longo do vale do rio, pássarospretos, bem-te-vis e periquitos grazinando em bandos. Certas moitas de gabiroba, gravatá e murici estavam com uma espessa teia de aranha muito abundante no lugar, em que o orvalho se prendia formando como se fosse um lençol alvíssimo. Uma Beleza! (ÉLIS, 1979, p. 86).

A materialidade da "rua paradíssima", da "frente da igreja", da "encosta fronteiriça doutra banda do rio" se imbricam com a ação das pessoas - com seus próprios olhares junto à paisagem -, com os animais - que como os pássaros, "desciam em nuvens sobre o chão" e sonorizavam a paisagem "cantando aqui e acolá" e "grazinando". As cores se avivam em "tufos verdes" e em "rubros da terra" na paisagem, e os gostos da paisagem se manifestam nas “moitas de gabiroba, gravatá e murici”.

É por meio ainda da narrativa dessa "paisagem viva" que Bernardo Élis demonstra um profundo conhecimento acerca das plantas do Cerrado. Retomando a idéia de "paisagem texto" elaborada por Cosgrove, como podemos observar especificamente na citação abaixo, do conto Os fuxicos da fonte do Taquari, o literato demonstra decodificar os códigos simbólicos que impregnam a paisagem ao nomear as plantas e arbustos com sua nomenclatura regional. É expresso por ele uma série de qualificações criadas, utilizadas e difundidas por pessoas que tem suas experiências diárias e excepcionais (RELPH, 1978) no bioma Cerrado:

\footnotetext{
${ }^{14}$ Bernado Élis produziu algumas obras, na verdade apostilas de estudos, sobre Goiás que envolviam aspectos sociais e físicos-naturais do estado, os quais eram utilizadas nas aulas que ministrava na Universidade Católica de Goiás e na Universidade Federal de Goiás como professor convidado. (ÉLIS, 1979)
} 
Era um desbarrancado grande, formando uma gruta que ia toda a vida. Na grota e nos altos adjacentes cresciam pés de pau: angico, jatobá, óleo, pindaíbas, cedros, embaúbas e gameleiras. Mais por baixo vinham murici, lobeiras, assa-peixe e, mais por derradeiro, vinham cansanção-de-leite, juá-brabo, são-caetano e tufos de capim tiririca e outros. A grota era sempre sombrosa. A gente vinha, que entrava, logo sentia que o tempo demudava para frioso e a gente sem querer pegava a espirrar. (ÉLIS, 1979, p. 131)

Bernardo Élis, do mesmo modo, vai além da materialidade da paisagem "extrínseca" ao indivíduo. A perspectiva expressionista presente em Veranico de Janeiro (VIERA,1999) permite com que sejam narradas "paisagens imaginárias" e carregadas de formas vivas, representando as próprias idéias confusas e disformes dos personagens frente a realidade - que é também abstrusa. Podemos observar isso no conto $A$ Enxada, pois os pensamentos confusos do personagem "Piano" - cujo desejo é uma enxada para plantar a roça para o coronel explorador - são marcados pela "fome, incompreensão, cansaço, dores nas munhecas que o sedenho cortou fundo, ardume das lapadas de sabre no lombo, revolta inútil, temor de tantas ameaças e nenhum vislumbre de socorro" (ÉLIS, 1979, p. 46). Estes mesmos pensamentos confusos se imbricam com a realidade e conformam no imaginário de "Piano" uma paisagem marcada por "alucinações":

Como é que pode ter tanto vaga-lume, meu Divino? - perguntava a si mesmo o camarada admirado da infinidade de pirilampos que riscavam a noite. Riscavam na copa dos muricis, dos paus-terra, das lobeiras da frente do rancho. Piscavam nos ares, aqueles traços de fogo imitantes fagulhas de queimada. "que nem Homero Ferreiro". Homero com avental de couro, a peitaria à mostra, metendo o malho no ferro que espirrava pirilampos, enquanto a foice ia saindo, a enxada ia saindo. Ah, enxada! (...) Pela frente do rancho, os vultos negros dos cupins, das lobeiras, das moitas de sarandis eram ferreiros arcados nas forjas fabricando enxadas, as faíscas dos caga-fogos espirrando a torta e a direita, no escuro da noite (ÉLIS, 1979, p. 51).

O dilema vivido por Piano, isto é, conseguir uma enxada para cultivar uma roça ou ser assassinado pelo coronel, influencia em seu olhar sobre a paisagem, cujo limite entre a realidade e o imaginário se torno tênue. Relph (1978, p. 14) nos oferece uma resposta acerca disso, pois, segundo ele,

as paisagens são em parte vistas e respondidas por um processo automático do subconsciente que lhes dá toda sorte de propriedades e valores simbólicos (...) na experiência semiconsciente da paisagem pode, claro, engendrar tantas respostas quantas forem as atitudes com respeito a ela. 


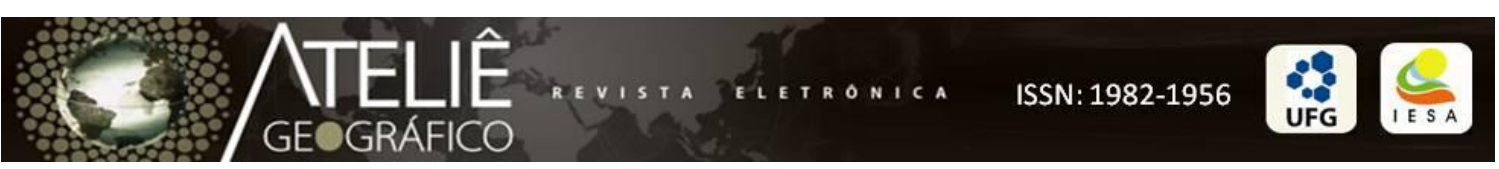

Uma vez que a conformação da paisagem se dá a partir do sensorial do indivíduo (SANTOS, 1997) e "Piano" vinha vivenciando atribulações pessoais e sofrendo terror psicológico por parte do coronel, ele obtém outras respostas da paisagem; onde, justamente, ele projetou seus próprios conflitos, medos, dilemas e contradições.

\section{Considerações finais}

As paisagens do Cerrado são explícitas na obra bernardiana. Além deste tratar das questões atinentes a sociedade; expressando as desigualdades, as relações de poder, os signos e relações simbólicas do sertão goiano, também aborda o meio físico-natural, no qual está contida esta sociedade - o que justamente conforma as paisagens. De certo modo, os aspectos físico-naturais também se tornam personagens na obra bernardiana; não são somente ambientadores, mas caracterizadores da narrativa. Assim, "veranico de janeiro", uma denominação que está presente no dito popular, representa não somente um período estacional do tempo metereológico, mas um elemento que compõe os enredos e influencia nas tramas dos contos da obra.

As paisagens do Cerrado são personagens em Bernardo Élis, entretanto, tornamos a repetir, não podemos perder de vista a dimensão artístico-poética de Veranico de Janeiro, pois, mesmo que o literato tenha se fundamentado em uma realidade palpável, a "inorganicidade" (MORAES, 2007) da literatura lhe permite ir além desta para construir o enredo. Daí nosso posicionamento de não entender a obra como representação fidedigna da realidade, mas sim, um construto de linguagem contido no campo literário que vagueia entre a realidade e a ficção.

\section{Referências}

ALMEIDA, Cristiane R. de. História e sociedade em Bernardo Élis: uma abordagem sociológica de o tronco. Dissertação de mestrado em sociologia. FCHF-UFG, 2003.

ALMEIDA, Maria G. de (orga.). Tantos Cerrados. Ed. Vieira: Goiânia, 2005.

Geoliteratura e o pretexto para diálogos com Brasigóis Felício. In: SOUSA, Andréia A. M. de. Geografia e literatura: a representação de Goiânia em fragmentos de Viver é Devagar de Brasigóis Felício. Goiânia: Kelps, 2010. p. 
BASTOS, Ana Regina V. R.. Espaço e literatura: algumas reflexões teóricas. In: Espaço e Cultura. N. 05, jan/jun de 1998. p. 55-66.

BERQUE, Augustin. A paisagem-marca, paisagem-matriz: elementos da problemática para uma geografia cultural. In: CORRÊA, R. L.; ROSENDAHL, Z. (orgs.) Paisagem, tempo e cultura. UERJ: Rio de Janeiro, 1998. p. 84-91.

BOURDIEU, Pierre. A ilusão biográfica. In: AMADO, Janaína; FERREIRA, Marieta de M. (orgs.). Usos e abusos da história oral. Rio de Janeiro: Ed. FGV. 1996. p.183-191.

BROSSEAU, Marc. Geografia e Literatura.In: CORREA, Roberto L.; ROSENDAHL, Zeny (orgs). Literatura, música e espaço. Rio de Janeiro: EdUERJ, 2007. p. 17-77.

BROSSEAU, Marc. O Romance: outro sujeito para a Geografia. In: CORRÊA, Roberto L.; ROSENDAHL, Zeny (orgs). Literatura, música e espaço. Rio de Janeiro: EdUERJ, 2007. p. $78-121$.

CHAVEIRO, E. F. A dança da natureza e a ruína da alma: Geografia e literatura - uma leitura possível. IN: Ateliê Geográfico, Goiânia-GO, v. 1, n. 2 dez/2007 p.174-186.

CIRQUEIRA, Diogo Marçal. Trajetórias socioespaciais de estudantes negras e negros da Universidade Federal de Goiás. Monografia de Graduação em Geografia. IESA-UFG, 2008.

Entre o corpo e a teoria: a questão étnico-racial na obra e na trajetória socioespacial de Milton Santos. Dissertação de mestrado em Geografia. Goiânia: IESA-UFG, 2010.

COSGROVE, Denis. A geografia está em toda parte: cultura e simbolismo nas paisagens humanas. In: CORREA, R. L.; ROSENDAHL, Z. (orgs.) Paisagem, tempo e cultura. UERJ: Rio de Janeiro, 1998. p. 92-123.

DE CERTEAU, Michel. A invenção do cotidiano: artes de fazer. Petrópolis: Vozes, 1984.

ÉLIS, Bernardo. Veranico de Janeiro. $4^{\text {a }}$ ed. Ed. Rio de Janeiro: José Olympio, 1979.

GOLDMANN, Lucien. Sociologia do romance. Rio de Janeiro: Paz e Terra, 1976.

HISSA, Cássio E. Vieira. A mobilidade das fronteiras: a inserção da geografia na crise da modernidade. Belo Horizonte: Editora UFMG, 2002.

KAUFMANN, Thomas da Costa. Introduction. In: Toward a Geography of Art. United States of America: The University of Chicago Press, 2004. p. 01-13.

LIMA, Solange T. de. Geografia e literatura: alguns pontos sobre a percepção de paisagem. In: Geosul. Florianópolis, v. 15, n.30, p. 7-33, jul./dez., 2000.

LOURES, Telma Mendonça. Os sentidos do silêncio nos contos de Bernardo Élis.

Dissertação de Mestrado. Goiânia: Programa de Pós-graduação em Letras (PUC-GO), 2010.

KUHN, Thomas. A estrutura das revoluções científicas. 5 ed. São Paulo: Perspectiva, 1998.

MORAES, Eliane Robert. A pornografia. Programa "Café Filosófico". São Paulo: TV Cultura, exibido em 22/11/2007. Disponível também no sítio www.cpflcultura.com.br.

MORIN, Edgar. A cabeça bem-feita: repensar a reforma. repensar o pensamento. Rio de Janeiro: Bertrand Brasil, 2000. 
NORONHA, Jovita Maria G.. Entrevista com Philippe Lejeune. In: Ipotesi, revista de estudos literários. Juiz de Fora, v. 06, n. 2. 2002. p. 21-30.

OLANDA, Diva A. M. "memórias do vento" e as paisagens citadinas. In: ALMEIDA, M. G. de; CHAVEIRO, E. F.; BRAGA, H. C. (orgs.). Geografia e Cultura. Ed. Vieira: Goiânia, 2008. p. 255-283.

OLANDA, Diva A. M.;OLANDA, Elson R.; Lugar da natureza e a natureza do lugar em obras de Carmo Bernardes. In: Anais EGAL 2009 - Programa on-line. Acessado no dia 20/01/2010 em < http://egal2009.easyplanners.info/> .

ORTENCIO, Bariani. Dicionário do Brasil Central. 2º̣ ed. Goiânia: ICBC, 2009.

PAZ, Octavio. Ambiguidad de la novela. In: poética, poesía e historia. $3^{\mathrm{a}}$ ed. México, FCE, 1972.

El arco y la lira: el poema, la revelación

POPPER, Karl. A lógica da pesquisa científica. São Paulo: Cultrix, 1993.

RAMOS, Graciliano. Vidas Secas. Ed. 81ª Rio de Janeiro: Record, 2005.

RELPH, Edward. As bases fenomenológicas da geografia. In: Geografia, Rio Claro, v. 4, n. , p. 1-25, 1978.

RIGONATO, Valney D.. A dimensão sociocultural das paisagens do cerrado goiano: o Distrito de Vila Borba. In: ALMEIDA, M. G. de (orga.). Tantos Cerrados. Ed. Vieira: Goiânia, 2005. p. 63-96.

SAID, E.; BARENBOIM, F. Paralelos e Paradoxos. São Paulo: Companhia das Letras, 2007.

SANTOS, M. Metamorfose do Espaço habitado. $5^{\text {a }}$ ed. São Paulo: Hucitec, 1997

SAUER, Carl O.. A morfologia da paisagem. In: CORREAA, R. L.; ROSENDAHL, Z. (orgs.) Paisagem, tempo e cultura. UERJ: Rio de Janeiro, 1998. p. 12-74.

SEEMANN, Jörn. Geografia, geograficidade e a poética do espaço: Patativa do Assaré e as paisagens da região do Cariri (Ceará). In: Ateliê Geográfico, Goiânia-GO, v. 1, n. 1 set/2007 p.50-73.

SEIERSTAD, Asne. A literatura na fronteira da realidade. In: SCHULER, F.; AXT, G; SILVA, J. M. da. Fronteiras do pensamento: retratos de um mundo complexo. São Leopoldo: Universidade do Vale do Rio dos Sinos, 2008. p. 427-438.

SOUZA, Lorena F. de. Corpos negros femininos em movimento: trajetória socioespaciais de professoras negras em escolas públicas. Dissertação de Mestrado em Geografia. IESA UFG, 2007.

SOUZA, Andréia A. M. de. Geografia e literatura: a representação de Goiânia em fragmentos de Viver é Devagar de Brasigóis Felício. Goiânia: Kelps, 2010.

TUAN, Yi-fu. Espaço e Lugar. São Paulo: Difel, 1983.

VERANICO. Enciclopédia Wikipédia. acessado no dia 28/08/2008 em $<$ http://pt.wikipedia.org/wiki/Veranico>. 
AGRITEMPO (Sistema de Monitoramento Agrometereológico). Veranico. Acessado no dia $28 / 08 / 2008$

$<$ http://www.agritempo.gov.br/modules.php?name=Encyclopedia\&op=content\&tid=207>.

VIEIRA, Emílio. O expressionismo em Bernado Élis e Siron Franco. Goiânia: UFG, 2000.

VILARINHOS, Maria L. R. Literatura, Território e Imaginário a ausência da palavra sertão nos romances do Rio Grande do Sul. In: Revista da ANPEGE. v. 3, p. 87 - 93 , 2007. acessado dia 17/01/2010 em <http://www.anpege.org.br/?op=5> .

Recebido para publicação em novembro de 2010.

Aprovado para publicação em junho de 2011. 